\title{
SPINEL FERRITES NANOPARTICLES FOR ALLOY STEEL PROTECTIVE LAYERS
}

\author{
${ }^{1}$ Martin OCHMANN, ${ }^{1}$ Fredericus M. A. LINDERHOF, 1,2Libor MACHALA \\ ${ }^{1}$ Department of Experimental Physics, Faculty of Science, Palacký University, Olomouc, Czech Republic, EU \\ ${ }^{2}$ Regional Centre of Advanced Technologies and Materials, Palacký University, Olomouc, \\ Czech Republic, EU
}

https://doi.org/10.37904/nanocon.2020.3722

\begin{abstract}
Covering layers might have very important role in improving performance of many mechanical parts. These layers are usually designed to protect a substrate from the environment and enhance mechanical properties such as hardness. Blackening is a classical approach that is very demanding on resources. This process is based on the alkalisation of surface atoms and the transformation of formed hydroxides to oxides. Such an approach inspired us to carry out experiments resulting in preparation of protective layers with similar properties, by using stoichiometric spinel ferrite nanoparticles $\left(\mathrm{MeFe}_{2} \mathrm{O}_{4}\right)$. Thus mechanical parts were covered with ferrite nanoparticles and heated in a furnace. Ferrite samples, which were used as precursor for the preparation of layers, were analysed with X-ray powder diffraction, energy dispersive X-ray spectroscopy and ${ }^{57} \mathrm{Fe}$ Mössbauer spectroscopy. The samples were analysed with ultrasonic hardness test, electron microscopy, and Mössbauer spectroscopy. The protection layers showed a higher hardness compared to untreated parts.
\end{abstract}

Keywords: Spinel ferrites, protective layer, Mössbauer spectroscopy, hardness test

\section{INTRODUCTION}

Spinel ferrites are a family of compounds similar to magnetic iron oxides, thus chemically magnetite can be considered as a spinel ferrite. The chemical formula of spinel ferrites is $\mathrm{MeFe}_{2} \mathrm{O}_{4}$, where $\mathrm{Me}$ is a divalent metal cation, e.g. $\mathrm{Zn}, \mathrm{Mg}, \mathrm{Ni}$ or $\mathrm{Mn}$ [1]. If the metal cation does not have a trivalent state, we can presume that the compound has high chemical stability. Spinel ferrites exist in normal, inverse or mixed modification. Both spinel modifications have the same $F d-3 m$ space group, but the distribution of cations can be determined by low temperature Mössbauer spectroscopy [2]. The physico-chemical properties of spinel ferrites are very convenient for passivation of surfaces, long lasting sensors, supercapacitors or contrast agents [1]. Thus the synthetic procedure is the key to tailor nanoparticles for specific purposes. The coprecipitation technique is very convenient for environmentally friendly synthesis of narrowly distributed nanoparticles [3], so it was employed in the study.

A surface treatment of mechanical parts is crucial to fabricate high quality products. Many metals lack rust resistance. Commonly used techniques are able to improve only the mechanical or chemical properties, e.g. galvanisation or painting. Other techniques are able to improve both mechanical and chemical properties, but require a relatively high amount of energy and resources, namely nitriding, anodising or blackening [4]. Blackening is a powerful technique to improve surface properties, hardness and chemical stability [5]. This process is applied to carbon steel such as high quality alloy steel used for guns. Military standards also mention blackening for surface treatment and testing of chemical resistance to moisture, salts and operating fluids (e.g. oil, gasoline). Blackening consists of submerging the part into highly alkaline solution with a high temperature. Leading to the formation of a hydroxide on the surface, which is then heated to form an oxide layer, which is chemically stable. This process is transformed into deposition of spinel ferrite nanoparticles and heating in a furnace for moderate temperature and time. 
The goal of the study is to investigate the influence of depositing zinc ferrite nanoparticles on the surface of an alloy steel plate. Basic properties of the prepared zinc ferrite nanoparticles were obtained with X-ray powder diffraction, Mössbauer spectroscopy and scanning electron microscopy. The phase composition of covered alloy steel plate was determined via the same analytical tools. The hardness is the main feature of prepared samples as the only mechanical property investigated during the study.

\section{MATERIALS AND METHODS}

\subsection{Preparation of spinel ferrite nanoparticles}

$\mathrm{FeCl}_{3} \cdot 6 \mathrm{H}_{2} \mathrm{O}, \mathrm{ZnCl}_{2}$ and $\mathrm{NaOH}$ (pure analytically) chemicals were purchased from PENTA, s.r.o. (Prague, Czech Republic). Ethanol was purchased from the company Verkon. Nanoparticles were prepared by precipitation of $\mathrm{Zn}^{2+}$ and $\mathrm{Fe}^{3+}$ ions by sodium hydroxide. The amount of ions were $n\left(\mathrm{Fe}^{3+}\right)=2 \mathrm{mmol}$, $n\left(\mathrm{Zn}^{2+}\right)=1 \mathrm{mmol}$ and $n\left((\mathrm{OH})^{-}\right)=9 \mathrm{mmol}$. The admixture was homogenised for $5 \mathrm{~min}$, then washed by deionised water. Finally, vacuum filtration was applied to collect the precipitate.

\subsection{Surface treatment of CL20ES plates}

CL20ES is an austenitic stainless steel powder of the chemical composition indicated in Table 1. The powder was sintered with a laser to form $25 \mathrm{~mm} \times 25 \mathrm{~mm} \times 3 \mathrm{~mm}$ metallic plate. This plate was then thermally treated and finally the plate was sandblasted by corundum abrasive of grain size of $70-150 \mathrm{um}$. The prepared nanoparticles were dispersed in ethanol and deposited on the plate, then the dispersions were dried at $80^{\circ} \mathrm{C}$ and finally the plates were heated in a furnace at the desired temperature for $2 \mathrm{~h}$. Sample Zn_Et_200 was heated at $200{ }^{\circ} \mathrm{C}$ and sample Zn_Et_400 was heated at $400{ }^{\circ} \mathrm{C}$.

Table 1 The chemical composition of CL20ES powder

\begin{tabular}{|c|c|c|c|c|c|c|c|c|}
\hline Component & Fe & Cr & Ni & Mo & Mn & Si & P & C, S \\
\hline Indicative value (\%) & Balance & $16.5-18.5$ & $10.0-13.0$ & $2.0-2.5$ & $0.0-2.0$ & $<=1.0$ & $<=0.045$ & $<=0.030$ \\
\hline
\end{tabular}

\subsection{X-ray diffraction (XRD)}

$\mathrm{X}$-ray powder diffraction (XRD) was used to determine the crystal structure and phase composition. The measurements were conducted using a Bruker D8 ADVANCE powder diffractometer operating in the BraggBrentano parafocusing geometry. The diffractometer was equipped with a LYNXEYE position sensitive detector and with a Co "Kalpha" radiation source. In addition, the divergence slit and Soller slits for the primary beam and the Fe "Kbeta" filter and Soller slits for the secondary beam were applied for the measurements.

\section{4. $\quad{ }^{57} \mathrm{Fe}$ Mössbauer spectroscopy}

To distinguish positions and chemical states of ${ }^{57} \mathrm{Fe}$ within the crystal structure in the samples, two Mössbauer spectrometers were used. The first spectrometer is a MS96 transmission Mössbauer spectrometer, the second a Conversion Electron Mössbauer Spectrometer (CEMS). Both operate in constant acceleration mode and make use of a ${ }^{57} \mathrm{Co}$ radioactive source in a Rh matrix. Samples were measured at room temperature [6]. The MS96 spectrometer was calibrated using a a-Fe calibration foil zeroing the isomer shift values. No external magnetic field was applied during measurement. The samples were measured at room temperature without applying an external magnetic field. MossWin 4.0 software was used for spectra evaluation [7].

The CEMS works in a reflective geometry and measures a Mössbauer spectrum based on conversion electrons which come from a depth up to $300 \mathrm{~nm}$ in the sample [8]. The CEMS makes use of a ФЭУ-85 photomultiplier as its detector. It is build into a Pfeiffer Vacuum Chamber to make the mean free path of the 
conversion electrons longer and an electric field is created using an Ortec 556 H High Voltage Power Supply between the detector and the sample to accelerate electrons towards the photomultiplier tube.

\subsection{Ultrasonic hardness test}

Hardness tests were performed with a ultrasonic portable hardness tester MET-U1A (Centre "MET", Russia). The tester is equipped with a probe that operates according to the ultrasonic contact impedance method (ASTM A 1038, DIN 50159). The hardness was measured on each side several times and an estimated hardness was used to calculate the improvement in hardness as a percentage.

\subsection{Energy dispersive X-ray spectroscopy}

VEGA3 LMU (TESCAN, Czech Republic) was used to collect EDS spectra, equipped with Si(Li) XFlash 410 EDS detector (Bruker, Germany). The primary energy of electrons was $30 \mathrm{keV}$ with a takeoff angle of $35^{\circ}$.

\section{RESULTS}

\subsection{Zinc ferrite characterisation}

Zinc ferrite was synthesised as described in the experimental section. XRD pattern corresponds to $F d-3 m$ space group, which is associated with spinel structure, because spinel ferrites have the same space group varying per cell parameter. The recognised peaks correspond exclusively to Fd3- $m$ space group pattern (Figure 1a).
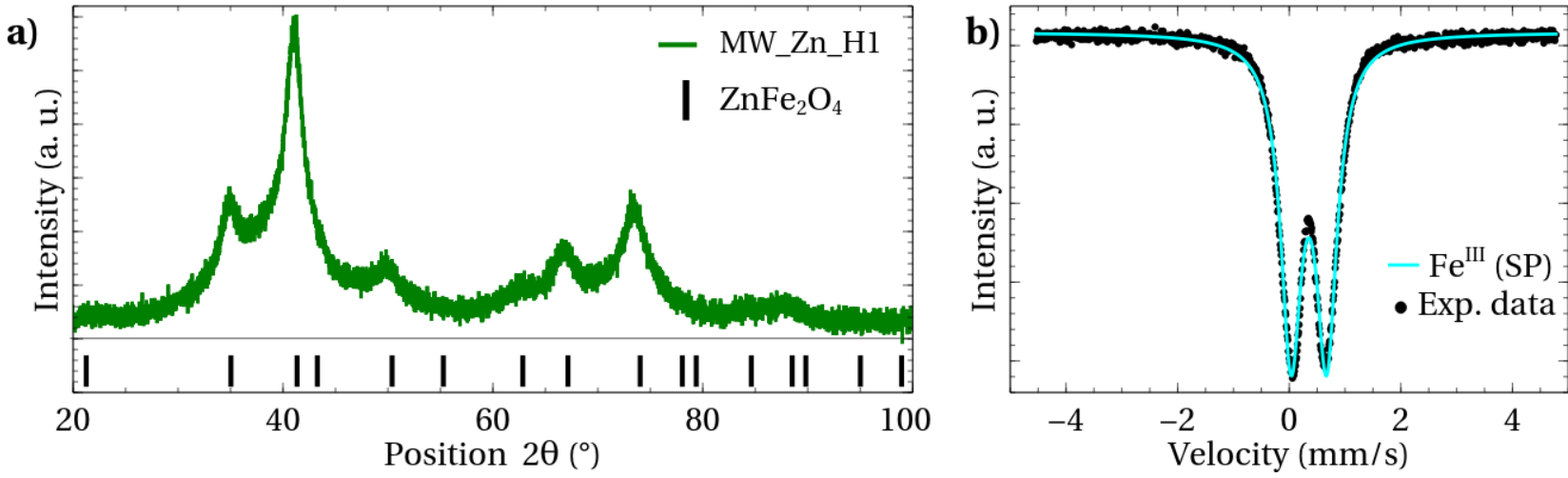

Figure 1 Prepared zinc ferrite MW_Zn_H1 (a) XRD pattern (b) ${ }^{57} \mathrm{Fe}$ Mössbauer spectroscopy

Room temperature transmission ${ }^{57} \mathrm{Fe}$ Mössbauer spectroscopy revealed only superparamagnetic nanoparticles containing $\mathrm{Fe}^{\mathrm{III}}$ (doublet spectral component) in Figure 1b. Generally, the size of superparamagnetic nanoparticles is under $20 \mathrm{~nm}$. The detailed parameters of Mössbauer spectral components are included in Table 2.

Table 2 Components and parameters of Mössbauer spectra of prepared zinc ferrite

\begin{tabular}{|c|c|c|c|c|c|c|c|}
\hline Sample & Component & $\begin{array}{c}\delta \\
\pm 0.01 \\
(\mathrm{~mm} / \mathrm{s})\end{array}$ & $\begin{array}{c}\Delta \mathrm{EQ} \\
\pm 0.01 \\
(\mathrm{~mm} / \mathrm{s})\end{array}$ & $\begin{array}{c}\text { Bhf } \\
\pm 0.3 \\
\text { (T) }\end{array}$ & $\begin{array}{l}\text { FWHM } \\
\pm 0.01 \\
(\mathrm{~mm} / \mathrm{s})\end{array}$ & $\begin{array}{l}\text { RA } \\
\pm 1 \\
(\%)\end{array}$ & Identification \\
\hline $\mathrm{MW} Z \mathrm{Zn} \_\mathrm{H} 1$ & Doublet & 0.35 & 0.60 & --- & 0.46 & 100 & $\mathrm{Fe}^{\mathrm{III}}(\mathrm{SP})$ \\
\hline
\end{tabular}

$\delta$ is the isomer shift (related to $\alpha-F e$ calibration foil at room temperature), $\Delta E_{Q}$ is the quadruple splitting energy, $B_{\mathrm{hf}}$ hyperfine magnetic field and RA is relative area. 
The element composition was evaluated by EDS, it identified peaks, that belongs to silicon, iron, copper, oxygen, zinc and carbon and the amount of individual elements are listed in Table 3. The spectrum has identified high intensity peaks, because the peaks of copper have low intensity they are not marked in Figure 2. The amount of iron, zinc and oxygen meet the synthetic procedure expectations, i. e. the ratio of $\mathrm{Fe}: \mathrm{Zn}$ is approximated to $2: 1$.

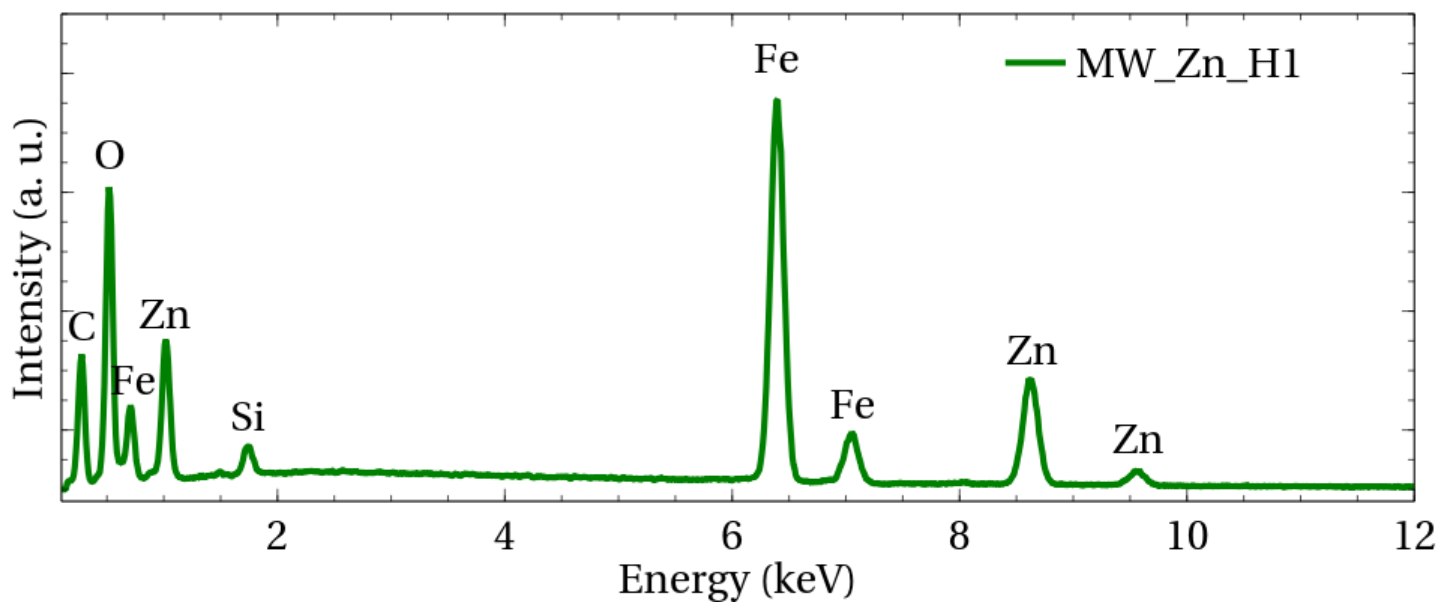

Figure 2 EDS spectrum of prepared zinc ferrite

Table 3 Quantification of EDS spectra of prepared zinc ferrite in weight \% with incertenity $0.5 \%$

\begin{tabular}{|c|c|c|c|c|c|c|}
\hline Sample & Fe & Zn & Si & C & 0 & Cu \\
\hline MW_Zn_H1 & 6.5 & 3.1 & 0.5 & 43.0 & 46.8 & 0.1 \\
\hline
\end{tabular}

\subsection{Covering layers characterisation}

The CL20ES sample plates with covering layer were analysed using conversion ${ }^{57} \mathrm{Fe}$ Mössbauer spectroscopy to obtain information about the surface phase composition. The investigation of layers was performed with a CEMS. The obtained spectra has 2 spectral components, a singlet is austenite, a doublet corresponding to zinc ferrite (Figure 3). The ferrite at the layers has different parameters as compared to the original spinel ferrite. The Zn_Et_200 doublet has similar parameters as untreated ferrite, but a higher temperature leads to a slight modification in the structure as presented in Table 4.
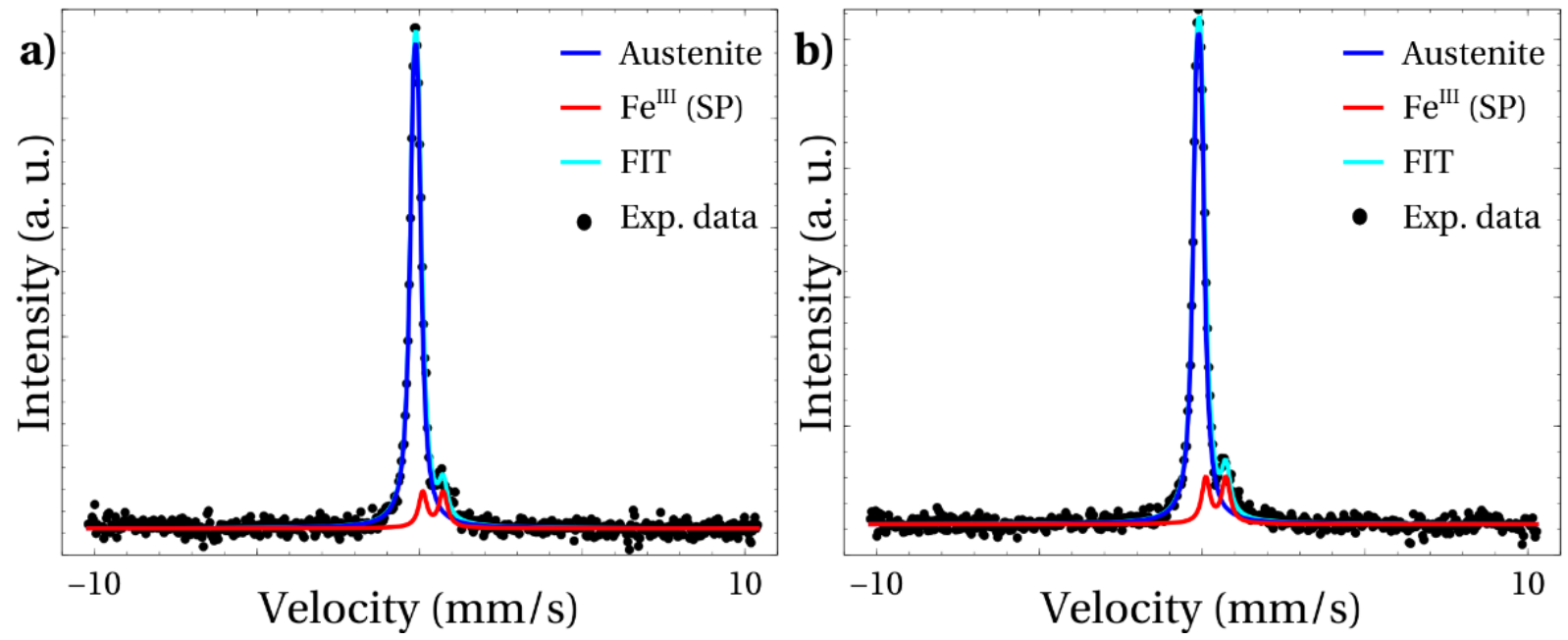

Figure 3 CEMS spectra of samples (a) Zn_Et_200 (b) Zn_Et_400 
Table 4 Components and parameters of CEMS spectra of plates covered with prepared zinc ferrite

\begin{tabular}{|c|c|c|c|c|c|c|c|}
\hline Sample & Component & $\begin{array}{c}\delta \\
\pm 0.02 \\
(\mathrm{~mm} / \mathrm{s})\end{array}$ & $\begin{array}{c}\Delta \mathrm{EQ} \\
\pm 0.02 \\
(\mathrm{~mm} / \mathrm{s})\end{array}$ & $\begin{array}{c}\text { Bhf } \\
\pm 0.3 \\
\text { (T) }\end{array}$ & $\begin{array}{c}\text { FWHM } \\
\pm 0.02 \\
(\mathrm{~mm} / \mathrm{s})\end{array}$ & $\begin{array}{l}\text { RA } \\
\pm 2 \\
(\%)\end{array}$ & Identification \\
\hline \multirow{2}{*}{ Zn_Et_200 } & Doublet 1 & -0.13 & 0.14 & --- & 0.28 & 89 & Austenite \\
\hline & Doublet 2 & 0.41 & 0.63 & --- & 0.30 & 11 & $\mathrm{Fe}^{\prime I I I}(\mathrm{SP})$ \\
\hline \multirow{2}{*}{ Zn_Et_400 } & Doublet 1 & -0.11 & 0.15 & --- & 0.27 & 86 & Austenite \\
\hline & Doublet 2 & 0.52 & 0.63 & --- & 0.30 & 14 & $\mathrm{Fe}^{\mathrm{III}}(\mathrm{SP})$ \\
\hline
\end{tabular}

$\delta$ is the isomer shift (related to $\alpha-F e$ calibration foil at room temperature), $\Delta E_{Q}$ is the quadruple splitting energy, $B_{\mathrm{hf}}$ hyperfine magnetic field and RA is relative area.

Hardness tests performed on each side of each plate show an improvement in hardness as indicated in Table 5 with the respective conditions of preparation.

Table 5 Improvement in hardness of prepared covering layers compared to untreated sides

\begin{tabular}{|c|c|c|c|}
\hline Sample & Alcohol & Temperature $\left({ }^{\circ} \mathrm{C}\right)$ & Improvement in hardness (\%) \\
\hline Zn_Et_200 & Ethanol & 200 & 8.6 \\
\hline Zn_Et_400 & Ethanol & 400 & 9.4 \\
\hline
\end{tabular}

\section{CONCLUSION}

The detailed composition of the prepared zinc ferrite is provided including phase and elemental composition. The fabrication of the covering layer on a CL20ES plate was successful as demonstrated in the result section by phase composition and hardness test. The results indicate improved hardness in all cases, in addition the relative hardness is even higher as the annealing temperature is higher. CEMS provided very useful information about the surface. The study revealed a need for covering layers not only to enhance mechanical properties, but also to passivate the surface. Spinel ferrites can be considered a good candidate to provide higher hardness and chemical stability to mechanical parts even in the case of alloy steel, which is considered as stainless.

\section{ACKNOWLEDGEMENTS}

The research has been supported by the Operational Programme Research, Development and Education - European Regional Development Fund, project "Hydrodynamic Design of Pumps" No. CZ.02.1.01/0.0/0.0/17049/0008408 of the Ministry of Education, Youth and Sports of the Czech Republic.

The authors appreciate the contribution in analysis and results of Vit Procházka, Vlastimil Vrba, Miroslav Mašláň, Tomáś Ingr and employees of VTP (University Palacký).

\section{REFERENCES}

[1] TATARCHUK, T., BOUOUDINA, M., VIJAYA, J. J. Spinel Ferrite Nanoparticles: Synthesis, Crystal Structure, Properties, and Perspective Applications. In: FESENKO, O., YATSENKO,L. Nanophysics, Nanomaterials, Interface Studies, and Applications. Springer International Publishing, 2017.

[2] DURRANI, S., NAZ, S., et al. Structural, impedance and Mössbauer studies of magnesium ferrite synthesized via sol-gel auto-combustion process. Journal of Saudi Chemical Society. 2017, vol. 21, no. 8, pp. 899-910.

[3] ATALAY, S., ERSÖZ, G. Novel Catalysts in Advanced Oxidation of Organic Pollutants. Springer, 2016. 
[4] A. FATTAH-ALHOSSEINI, H. Y. Comparison of anti-corrosive properties between hot alkaline nitrate. Journal of Alloys and Compounds. 2016, vol. 676, pp. 474-480.

[5] REGHURAJ, A., SAJU, K. Black oxide conversion coating on metals: A review of coating techniques and adaptation for SAE 420A surgical grade stainless steel. In: Materials today: proceedings. 2017, vol. 4, no. 9, pp. 9534-9541.

[6] PECHOUŠEK, J., JANČíK, D., FRYDRYCH, J., NAVAŘíK, J., NOVÁK, P. Setup of Mössbauer spectrometers at RCPTM. In: Mossbauer Spectroscopy in Materials Science - 2012. American Institute of Physics, 2012, pp 186 193.

[7] KLENCSÁR, Z. Mössbauer spectrum analysis by Evolution Algorithm. Nuclear Instruments and Methods in Physics Research Section B Beam Interactions with Materials and Atoms. 1997, vol. 129, no. 4, pp. 527-533.

[8] PROCHÁZKA, V. Neobvýklá Mössbauerova spektroskopie. Olomouc: Univerzita Palackého v Olomouci, 2014. 